\title{
The course of diabetic retinopathy following cataract surgery in eyes previously treated by laser photocoagulation
}

\author{
Ayala Pollack, Hana Leiba, Amir Bukelman, Simon Abrahami, Moshe Oliver
}

\begin{abstract}
The course of diabetic retinopathy following extracapsular cataract extraction with posterior chamber lens implantation in eyes previously treated by laser photocoagulation for diabetic retinopathy was retrospectively studied in 33 eyes (33 patients). In 20 eyes $(61 \%)$ there was no change in the retinal status postoperatively. In $13(39 \%)$ there was postoperative progression of diabetic retinopathy compared with the fellow non-operated eye, in which progression occurred in nine eyes $(27 \%)$. The severity of the preoperative status affected the incidence of progression. Four eyes $(12 \%)$ developed complications of diabetic retinopathy - that is, rubeosis iridis and vitreous haemorrhage - which regressed after lasering. Cystoid macular oedema developed in 13 eyes (39\%) and its incidence varied according to the postoperative course of diabetic retinopathy. The majority of the eyes showed a postoperative improvement in vision.
\end{abstract}

A number of studies have shown that diabetic retinopathy may progress after cataract extraction. ${ }^{1-11}$ In our earlier study of the course of diabetic retinopathy following cataract extraction we found that the preoperative presence of diabetic retinopathy is a risk factor for its postoperative progression. ${ }^{10}$ Excluded from that study however were eyes that, prior to surgery, had received laser treatment for established diabetic retinopathy. It was of interest to find out whether the preoperative laser treatment in those eyes had affected the postoperative course of diabetic retinopathy. In order to address this question we retrospectively reviewed the course of diabetic retinopathy in diabetic eyes that underwent extracapsular cataract extraction and in which the retinopathy had been treated by laser treatment at least 3 months prior to the cataract surgery.

Ophthalmology, Kaplan

Hospital, Rehovot, Israel

A Pollack

H Leiba

A Bukelman

S Abrahami

M Oliver

affiliated to the Hebrew

University-Hadassah

Medical School,

Jerusalem, Israel

A Pollack

M Oliver

Correspondence to:

A Pollack, MD, Department

of Ophthalmology, Kaplan

Hospital, 76100 Rehovot,

Israel.

Accepted for publication

27 September 1991 procedure on one eye only; (3) no other ocular disorders; (4) laser treatment for established diabetic retinopathy applied at least 3 months before surgery. The laser treatment had consisted of panretinal photocoagulation for proliferative or very severe non-proliferative diabetic retinopathy and/or focal or grid argon green laser photocoagulation for macular oedema. Thus all of the patients had been diagnosed as having either advanced non-proliferative or proliferative diabetic retinopathy; (5) a postoperative followup period of at least 1 year; (6) a fundal examination prior to or within 3 days after surgery as a baseline examination for future comparison with the postoperative retinal course; (7) at least one additional fundal examination during three distinct periods within the first year of follow-up. The first follow-up period, Fl, was from the beginning of the second week after surgery to the end of the third month. The second, F2, was between 4 and 6 months after surgery, and the third, F3, was between the seventh and the twelfth month.

For each patient a standardised medical protocol was completed, giving detailed demographic and clinical information including duration of diabetes mellitus, presence of other systemic diseases, and medications. During each followup period the ocular findings were recorded. These included best corrected visual acuity, applanation tonometry, biomicroscopy, Goldman three-mirror examination, and indirect ophthalmoscopy. Also recorded were the findings of postoperative fluorescein angiography and the results of laser treatment applied during the follow-up periods F1 and F3. Fundal examinations, colour fundus photographs, and fluorescein angiography readings were performed by a retinal specialist.

On the basis of the diabetic retinal findings two groups were identified. The first, defined as the 'no change' group, consisted of eyes in which no postoperative aggravation of diabetic retinopathic changes was observed. The second, termed the 'progression' group, consisted of eyes in which diabetic retinopathy progressed following surgery. Progression was considered to have occurred when: (1) after surgery a patient with pre-existing non-proliferative diabetic retinopathy (NPDR) showed postoperative aggravation of the non-proliferative changes with or without the occurrence or aggravation of cystoid macular oedema (CMO) or showed development of proliferative diabetic retinopathy (PDR); or (2) a patient with PDR showed postoperative recurrence of proliferative changes or development of non-proliferative changes in the posterior pole, with or without the occurrence or aggravation of CMO. The postoperative occurrence of CMO alone without other evidence of aggravation of diabetic retinopathy was not regarded as progression of retinopathy since CMO is a 
Table 1 Clinical features of patients with and without progression of diabetic retinopathy following cataract surgery

\begin{tabular}{|c|c|c|}
\hline & $\begin{array}{l}\text { No change } \\
(n=20 \text { cases }) \\
(61 \%)\end{array}$ & $\begin{array}{l}\text { Progressiont } \\
(n=13 \text { cases }) \\
(39 \%)\end{array}$ \\
\hline \multirow[t]{2}{*}{$\begin{array}{l}\text { Mean age (SD) (range), years } \\
\text { Mean duration of } D M \ddagger(S D) \text { (range), years }\end{array}$} & $\begin{array}{l}68(7)(42-80) \\
17 \cdot 3(8)(1-30)\end{array}$ & $\begin{array}{l}61 \cdot 4(8)(32-80) \\
16 \cdot 4(6)(10-30)\end{array}$ \\
\hline & \multicolumn{2}{|l|}{ No of patients (\%) } \\
\hline Male/female & $12: 8(60: 40)$ & $6: 7(46: 54)$ \\
\hline \multicolumn{3}{|l|}{ Management of DM } \\
\hline Diet & - & - \\
\hline Oral agents & $12(60)$ & $5(38)$ \\
\hline Insulin/insulin and oral & $8(40)$ & $8(62)$ \\
\hline \multicolumn{3}{|l|}{ Vascular disease: } \\
\hline Hypertension & $8(40)$ & $4(31)$ \\
\hline Cardiac & $2(10)$ & $1(8)$ \\
\hline Hypertension and cardiac & $2(10)$ & $2(15)$ \\
\hline Other & $5(25)$ & $3(23)$ \\
\hline
\end{tabular}

*Without postoperative progression of diabetic retinopathy.

tWith postoperative progression of diabetic retinopathy.

known complication after cataract surgery even in the absence of diabetic retinopathy.

The $\chi^{2}$ test was used for statistical analysis.

\section{Results}

Of the 33 patients 18 were men and 15 were women. The mean age at the time of surgery was 64.7 years (range 32 to 80 years) and the mean duration of diabetes mellitus was 16.9 years (ranging from 1 to 30 years). Prior to surgery 22 eyes had NPDR, of which seven also had CMO, and 11 eyes had PDR, one of them with CMO.

Following cataract surgery 20 eyes (61\%) showed 'no change' in retinal status and $13(39 \%)$ showed 'progression' of diabetic retinopathy. In the no change group, although none showed postoperative aggravation of diabetic retinopathy, CMO development was observed in five eyes, three of them with NPDR and two with PDR. In the progression group only one eye with preoperative NPDR developed PDR after surgery, and this progression was accompanied by CMO. Following cataract surgery six eyes in which PDR had been treated preoperatively by laser photocoagulation developed new areas or progression of neovascularisation. Of these eyes two developed vitreous haemorrhage, one developed rubeosis iridis, and one developed both rubeosis iridis and vitreous haemorrhage. In the group of 13 eyes that showed postoperative progression of retinopathy eight eyes, five with NPDR and three with PDR preoperatively, developed CMO as well. Thus a total of 13 eyes which initially did not have CMO developed it after cataract surgery.

Table 1 compares the clinical features of patients with and without postoperative progression. Differences between the two groups were not significant, although more patients with progression than with no change were on insulin treatment for the management of diabetes.

Correlation between the preoperative status of diabetic retinopathy and its postoperative course revealed that of 22 eyes with preoperative NPDR the postoperative retinal status remained unchanged in $15(68 \%)$ and progressed in seven $(32 \%)$. Of 11 eyes with preoperative PDR the postoperative retinal status remained unchanged in five (45\%) and progressed in six (55\%).
Of the 13 eyes with postoperative progression of diabetic retinopathy seven had NPDR and six had PDR. Among the former group progression of retinopathy occurred in five eyes in the $F 1$ period, in one eye in the $\mathrm{F} 2$ period, and in one eye in the $F 3$ period. In the latter group progression occurred in one eye in the F1 period, in three eyes in the $\mathrm{F} 2$ period, and in two eyes in the F3 period.

Of 13 eyes with postoperative evidence of progression of diabetic retinopathy, 10 received additional laser treatment within 1 year of cataract surgery, because of the following indications: retinal neovascularisation (two eyes), rubeosis iridis (one eye), vitreous haemorrhage (one eye), rubeosis iridis and vitreous haemorrhage (one eye) and aggravation of NPDR (five eyes). Following laser treatment the five eyes with PDR showed resorption of vitreous haemorrhage and regression of rubeosis iridis and retinal neovascularisation. In the other five eyes with NPDR one eye showed an improvement in the retinal status, three showed no further changes, and one showed further progression of the retinopathy in spite of treatment. Three eyes were not treated; in two of them (with NPDR) the retinopathy remained stable and in one eye (with PDR) it deteriorated with development of vitreous haemorrhage towards the end of the 1 year period of follow-up. The latter was treated successfully after the end of the 1 year period of follow-up.

Good visual acuity of $6 / 12$ or better was achieved in only $24 \%$ of the study group (Table 2). However, a comparison between the pre- and postoperative visual acuity revealed that the majority of eyes showed at least some improvement (Fig 1). The most frequent cause of the low visual acuity was the presence of CMO (Table 3 ).

Follow-up of the 33 non-operated fellow eyes over 1 year revealed no change in the retinal status of $24(73 \%)$ of them and progression of diabetic retinopathy in nine (27\%). Among the former group retinopathy remained unchanged in 17 of the fellow operated eyes $(71 \%)$ and progressed in seven (29\%). Among the latter group retinopathy progressed in six of the fellow operated eyes $(66.6 \%)$ and remained unchanged in three (33.3\%). A symmetric course was seen in 23 patients $(70 \%)$.

\section{Discussion}

Postoperative progression of diabetic retinopathy occurred in $39 \%$ of the eyes in this series. This rate is similar to that in diabetic eyes that underwent the same surgical procedure but did not receive laser treatment prior to surgery $(38 \%),{ }^{10}$ and is slightly higher than that among the fellow non-operated eyes (27\%). Furthermore when we examined the state of retinopathy in non-operated eyes in relation to the postoperative course in the fellow operated eyes we found that where the operated eye showed no change in retinal status the non-operated eye tended also to remain unchanged $(71 \%)$, while if the operated eye showed progression there was a tendency to progression in the non-operated eye as well (66.6\%).

Ruiz and Saatci also found progression of 
Table 2 Final visual acuity results at the end of 1 year of postoperative follow-up

\begin{tabular}{|c|c|c|c|c|c|}
\hline \multirow[b]{2}{*}{ Visual acuity } & \multicolumn{2}{|l|}{$\begin{array}{l}\text { No change } e^{\star} \\
(n=20 \text { eyes })\end{array}$} & \multicolumn{2}{|l|}{$\begin{array}{l}\text { Progressiont } \\
(n=13 \text { eyes })\end{array}$} & \multirow{2}{*}{$\begin{array}{l}\text { Total } \\
(n=33) \\
\text { No. }(\%)\end{array}$} \\
\hline & $\begin{array}{l}\text { Without } C M O \mp \\
(n=10)\end{array}$ & $\begin{array}{l}\text { With CMO } \\
(n=10)\end{array}$ & $\begin{array}{l}\text { Without } C M O \\
(n=2)\end{array}$ & $\begin{array}{l}\text { With CMO } \\
(n=11)\end{array}$ & \\
\hline $\begin{array}{l}\geq 6 / 12 \\
6 / 15-6 / 30 \\
<6 / 30\end{array}$ & $\frac{3}{7}$ & $\begin{array}{l}1 \\
5 \\
4\end{array}$ & $\frac{-}{2}$ & $\begin{array}{l}4 \\
3 \\
4\end{array}$ & $\begin{array}{r}8(24) \\
8(24) \\
17(52)\end{array}$ \\
\hline
\end{tabular}

^Without postoperative progression of diabetic retinopathy.

With postoperative progression of retinopathy.

fCystoid macular oedema.

diabetic retinopathy after extracapsular cataract extraction and posterior chamber lens implantation in eyes with laser-ablated retina. ${ }^{\text {" Neverthe- }}$ less the results of our study appear to indicate that preoperative laser treatment of eyes with advanced retinopathy attenuates the postoperative retinopathy course. This may be inferred from the following findings: (1) the rate of postoperative progression in eyes with advanced preoperative diabetic retinopathy did not differ significantly from the fellow non-operated eyes; (2) the course of progression in many of the nonoperated eyes resembled that in the operated fellow eye; (3) the rate of postoperative progression in eyes treated with laser for advanced preoperative diabetic retinopathy was similar to that in eyes with mild diabetic retinopathy. ${ }^{10}$

The overall incidence of postoperative progression of diabetic retinopathy was $39 \%$. The rate varied however according to the preoperative severity of the retinopathy, from $32 \%(7 / 22)$ in eyes with preoperative NPDR to $55 \%(6 / 11)$ in eyes with preoperative PDR. This is in line with previous observations that the postoperative prognosis of diabetic retinopathy depends on its

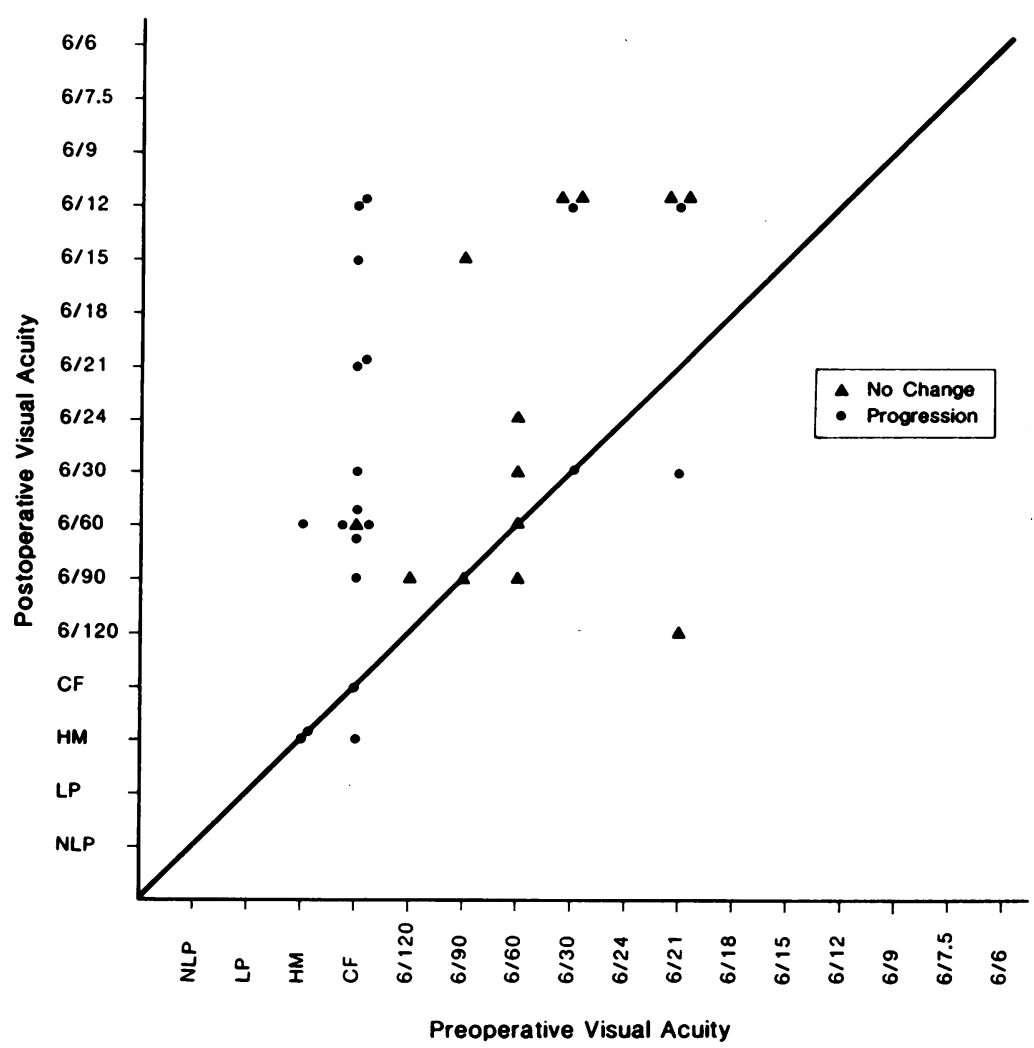

Figure 1 Scattergram of best corrected visual acuity before cataract surgery and at 1 year of follow-up. ( $\mathbf{\Delta})$ No change=eyes without postoperative progression of diabetic retinopathy. (O) Progression=eyes with postoperative progression of retinopathy. NLP=no light perception; $L P=$ light perception; $H M=$ hand movements; $C F=$ counting fingers.
Table 3 Reasons for poor visual acuity (less than 6/12)

\begin{tabular}{lll}
\hline & $\begin{array}{l}\text { No change } \\
(n=16)\end{array}$ & $\begin{array}{l}\text { Progressiont } \\
(n=9)\end{array}$ \\
\hline Cystoid macular oedema & 8 & 7 \\
Diabetic maculopathy & 3 & \\
Vitreous haemorrhage & $2 \ddagger$ & 1 \\
Optic atrophy & 2 & 1 \\
Opacification of posterior capsule & 1 & \\
\hline \#Without postoperative progression of diabetic retinopathy. \\
+With postoperative progression of retinopathy. \\
†Vitreous haemorrhage present prior to cataract surgery.
\end{tabular}

preoperative severity. ${ }^{70}$ Deterioration usually took the form of aggravation of a pre-existing state, either of NPDR or of PDR, and only one eye showed progression from NPDR to PDR. When progression developed in eyes with preoperative NPDR it was evident usually within 3 months of surgery. In eyes with preoperative PDR, aggravation of retinopathy tended to appear more than 3 months after surgery.

Cystoid macular oedema often occurred after surgery, and new cases of CMO were seen in 13 eyes (39\%); its incidence varied, however, with the postoperative retinal course. It developed even in $25 \%(5 / 20)$ of eyes without postoperative aggravation of retinopathy, and in as many as $61 \cdot 5 \%(8 / 13)$ of eyes with postoperative retinopathic progression. Cheng and Franklin ${ }^{7}$ also found that CMO occurs more frequently in eyes with diabetic retinopathy than without it, whereas Ruiz et $a l^{\prime \prime}$ found only an $8 \%$ incidence of CMO development following extracapsular cataract extraction.

Of the 13 eyes in the present series that showed progression of retinopathy six exhibited aggravation of PDR; of these four developed PDRassociated complications including vitreous haemorrhage and rubeosis iridis. None of the eyes progressed to neovascular glaucoma. Interestingly all of the eyes with complications of PDR had already developed them prior to surgery; in all cases the complications regressed after lasering but reappeared following surgery. In three eyes they disappeared again after additional laser treatment during the year of followup; in the fourth, vitreous haemorrhage appeared towards the end of the study period and its outcome is therefore not recorded here. The inclusion of eyes with advanced diabetic retinopathy may explain the occurrence of complications in this group in spite of preoperative lasering, especially the development of rubeosis iridis in two eyes. In a previously described nonlasered group ${ }^{10}$ these complications, although expected, did not occur even though that series unlike the present one - included eyes that underwent intracapsular cataract extraction considered as a risk factor for development of rubeosis. ${ }^{+1213}$ On the other hand the diabetic retinopathy in those eyes was less advanced on average than in the present series.

Visual acuity of at least 6/12 was achieved in $24 \%$ of our patients, and an additional $24 \%$ achieved vision between $6 / 15$ and $6 / 30$. In eyes with severe diabetic retinopathy, and especially in those with maculopathy, improvement in vision may be a more relevant criterion of success than the final visual acuity. As shown in Figure 1 a majority of eyes showed improvement in vision 
postoperatively even though many of these eyes had advanced diabetic retinopathy and CMO occurred frequently (Table 3 ).

The results of this study indicate that in eyes with advanced diabetic retinopathy laser treatment applied at least 3 months prior to cataract surgery may stabilise the retinopathy but does not prevent its postoperative progression. The question then arises: should patients with cataract but with adequate fundus visualisation receive laser treatment even when the diabetic retinopathy is not severe enough to meet the criteria for laser treatment outlined by the Diabetic Retinopathy Multicentre Studies? Until this issue is tested in randomised clinical trials we suggest that these patients be closely followed after cataract surgery and any progression of their retinopathy be treated promptly.

1 Apple DJ, Mamalis N, Loftfield K, et al. Complications of intraocular lenses. A historical and histopathological review. Surv Ophthalmol 1984: 29: 1-25.

2 Alpar JJ. Cataract extraction and diabetic retinopathy. $7 \mathrm{Am}$ Intraocul Implant Soc 1984; 10: 433-7.
3 Alpar JJ. Diabetes, cataract extraction and intraocular lenses. F Cataract Refract Surg 1987; 13: 43-6.

4 Pavase T, Insler MS. Effects of extracapsular cataract extraction with posterior chamber lens implantation on the development of neovascular glaucoma in diabetics. F Cataract Refract Surg 1987; 13: 197-201.

5 Jaffe GJ, Butron TC. Progression of nonproliferative diabetic retinopathy following cataract extraction. Arch Ophthalmol 1988; 106: 745-9.

6 Prasad P, Setna PH, Dunne JA. Accelerated ocular neovascularisation in diabetics following posterior chamber lens

7 Cheng $\mathrm{H}$, Franklin SL. Treatment of cataract in diabetics with and without retinopathy. Eye 1988; 2: 607-14.

8 Cunliffe IA, Flanagan DW, George NDL, Aggarwaal RJ, Moore AT. Extracapsular cataract surgery with lens implantation in diabetics with and without proliferative retinopathy. Brf Ophthalmol 1991; 75: 9-12.

9 Pollack A, Dotan S, Oliver M. The course of diabetic retinopathy following cataract surgery. $\mathrm{Br} \mathcal{F}$ Ophthalmol 1991; 75: 2-8.

10 Pollack A, Leiba $H$, Oliver $M$. Progression of diabetic retinopathy after cataract surgery. Brf Ophthalmol 1991; 75 : 547-551.

11 Ruiz TS, Saatci OA. Posterior chamber intraocular lens implantation in eyes with inactive and active proliferative implantation in eyes with inactive and active proliferative

12 Aiello LM, Wand M, Liang G. Neovascular glaucoma and vitreous hemorrhage following cataract extraction in patients with diabetes mellitus. Ophthalmology 1983; 90: 814-9.

13 Poliner LS, Christianson DJ, Escoffery RF, Kolker AE Gordon ME. Neovascular glaucoma after intracapsular and extracapsular cataract extraction in diabetic patients. Am F Ophthalmol 1985; 100: 637-43. 